\title{
Calibration capabilities at PTB for radiation thermometry, quantitative thermography and emissivity
}

\author{
by I. Müller*, A. Adibekyan*, B. Gutschwager*, E. Kononogova*, S. König*, C. Monte*, M. Reiniger*,
} and J. Hollandt*

*Physikalisch-Technische Bundesanstalt, Department Detector Radiometry and Radiation Thermometry, Abbestr. 2-12, 10587, Berlin, Germany, ingmar.mueller@ptb.de

\begin{abstract}
The calibration capabilities of the Physikalisch-Technische Bundesanstalt (PTB), the national metrology institute of Germany, are described. PTB offers calibrations for non-contact thermometry at the highest metrological level. For this purpose, PTB operates measurement and calibration facilities with national standards in air and under vacuum to characterize radiation thermometers, infrared camera systems and radiation standards. Our aim is to provide and develop application-specific traceability concepts for infrared radiation thermometry, infrared radiometry, for quantitative thermography and emissivity measurement.
\end{abstract}

\section{Introduction}

Non-contact temperature sensing and infrared radiometry sees many applications beginning with ear thermometers for the medical field, thermography of buildings, process control in industry and science, telescopes to space based remote sensing. At PTB we provide traceability for radiometric measurements in all these fields to the International System of Units by means of calculable blackbody radiation based on Planck's law. In the working group "Infrared radiation thermometry" several high-quality heat pipe cavity radiators are operated as national standards as well as large area plate radiators covering the temperature range from $-170{ }^{\circ} \mathrm{C}$ to $962{ }^{\circ} \mathrm{C}$. The radiation thermometric characterization and calibration of a thermal imager traceable to the International Temperature Scale of 1990 is crucial for every quantitative temperature measurement with that imager with a stated uncertainty. Thermal imagers allow fast spatially resolved temperature measurements but the requirements to calibrate thermal imagers are much higher as compared to radiation thermometers.

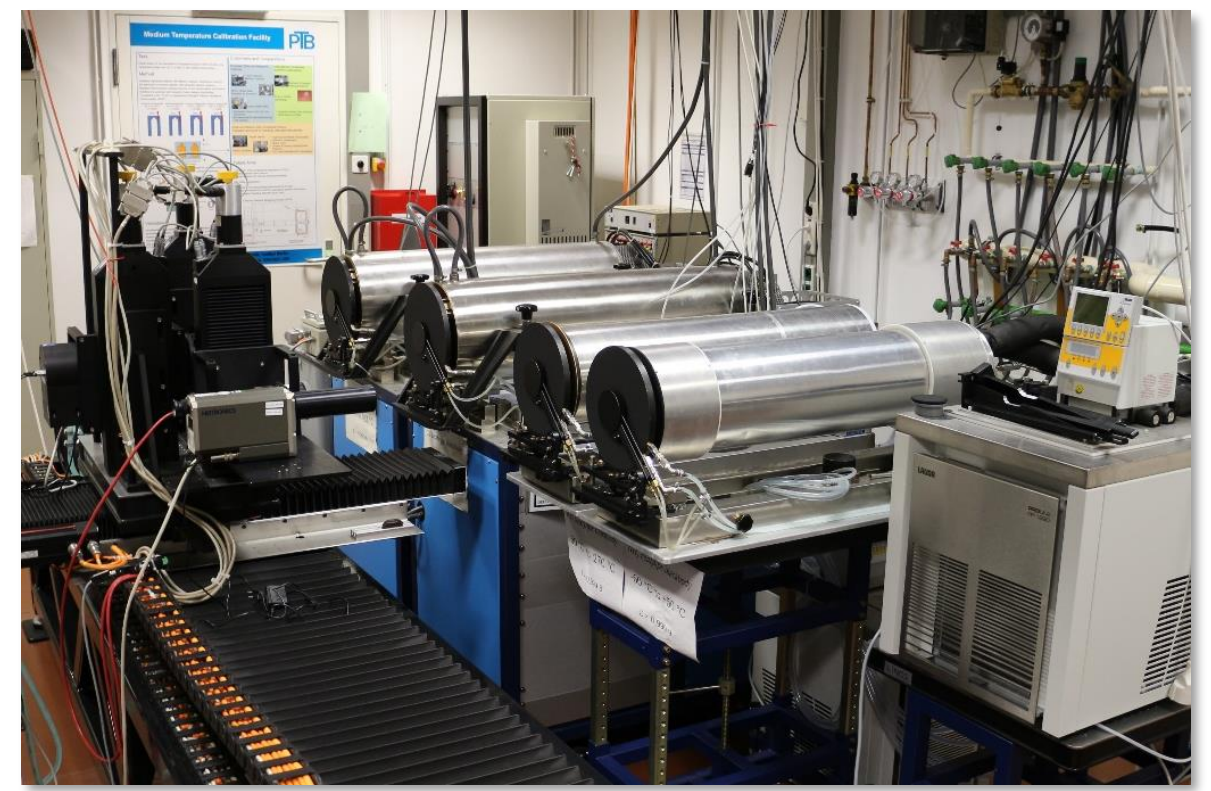

Figure 1 Germanys national standards for radiation temperatures from $-60{ }^{\circ} \mathrm{C}$ to $962{ }^{\circ} \mathrm{C}$. 


\section{Calibration services}

The instrumentation of our calibration labs is intended to meet the highest metrological demands, employing highquality radiation sources and metrology-grade measurement equipment. We provide traceability for customers in science, industry and national standard laboratories in many countries.

\subsection{Radiation sources for calibration services for radiation thermometry}

At PTB, a dedicated calibration facility for radiation thermometers and radiation sources is operated [1]. Four highquality heat pipe cavity radiators covering the temperature range from $-60^{\circ} \mathrm{C}$ to $962^{\circ} \mathrm{C}$ are available (see Figure 1). The radiance temperatures $t_{\mathrm{s}, 90}$ at the calibration points are set by means of Standard Platinum Resistance Thermometers (SPRTs). The temperature of the blackbodies is measured according to the ITS-90 via the SPRTs positioned very close to the bottom of the cavity and in good thermal contact with the heat transfer agent. The conical cavity bottom has an angular aperture of $120^{\circ}$. The radiance temperatures from $-60^{\circ} \mathrm{C}$ to $50^{\circ} \mathrm{C}$ are provided by an ammonia heat pipe blackbody with an emissivity of 0.9999 . The radiance temperatures from $50^{\circ} \mathrm{C}$ to $270{ }^{\circ} \mathrm{C}$ are provided by a water heat pipe blackbody with an emissivity of 0.9994 . The radiance temperature range from $250{ }^{\circ} \mathrm{C}$ to $650{ }^{\circ} \mathrm{C}$ is covered by a caesium heat pipe blackbody with an emissivity of 0.9996 , while the highest temperature range from $500{ }^{\circ} \mathrm{C}$ to $962^{\circ} \mathrm{C}$ is covered by a sodium heat pipe blackbody also with an emissivity of 0.9996 [1]. With these blackbodies, the radiance temperatures of the sources can be made available to customers with expanded uncertainties $(k=2)$ between generally $0.060 \mathrm{~K}$ to $0.262 \mathrm{~K}$ depending on the observed wavelength and temperature of the source. In addition to the heat pipe cavity radiators, we provide calibrations for calibrators for infrared ear thermometers in accordance with EN 12470-5:2003 by means of immersion blackbody radiators with an expanded uncertainty $(k=2)$ of $0.050 \mathrm{~K}$.

For the calibration of customer radiators several stable high-quality transfer radiation thermometers working at $1.6 \mu \mathrm{m}$, $3.9 \mu \mathrm{m}$ and from $8 \mu \mathrm{m}$ to $14 \mu \mathrm{m}$ are available. With these radiation thermometers cavity or plate type radiators can be calibrated with very low uncertainties by a comparison with PTB's heat pipe blackbodies.

\subsection{Radiation sources for calibration services for quantitative thermography}

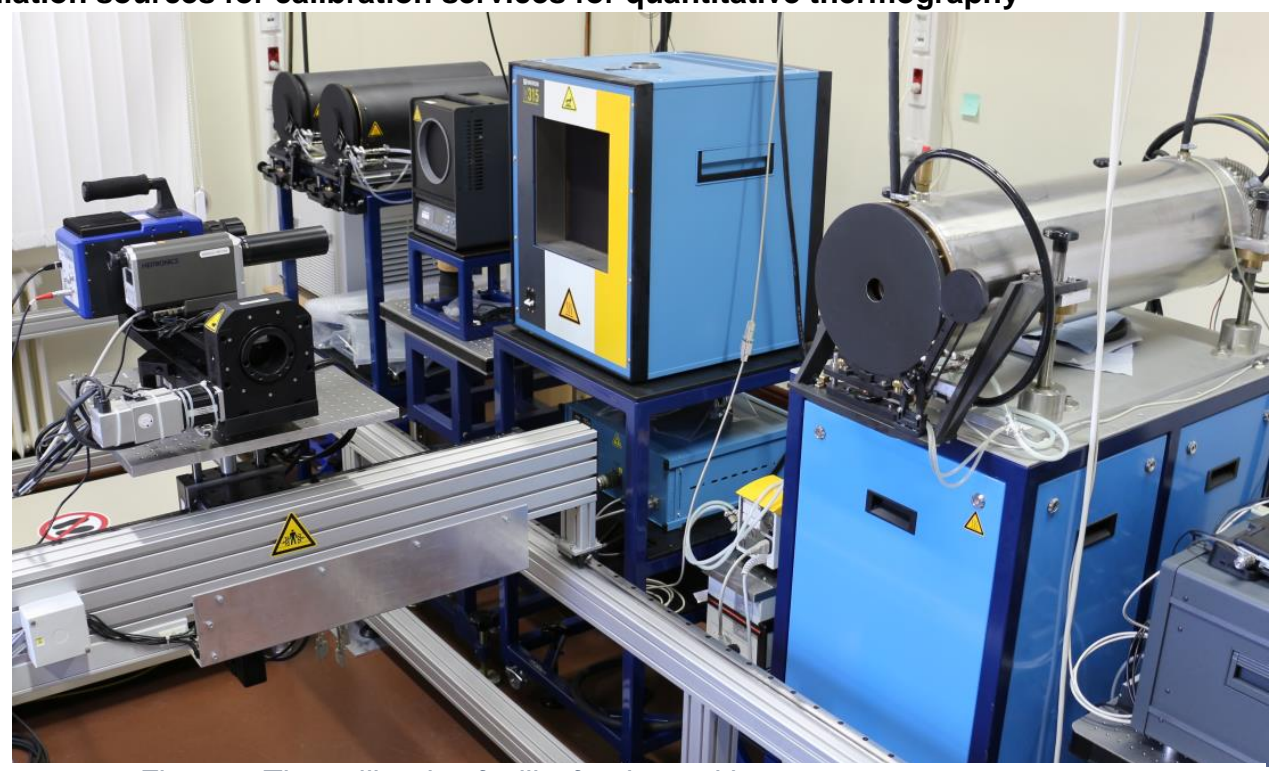

Figure 2 The calibration facility for thermal imagers.

For the calibration of thermographic cameras an additional calibration facility (see Figure 2) has been established at PTB that combines high emissivity and very low uncertainty heat pipe blackbodies with large area plate radiators for the calibration of detector arrays [2]. The heat pipe blackbodies are used to calibrate the central sensor field of thermography systems while the large area plate radiators are typically used to irradiate a larger fraction or the whole area of the sensor with known temperature radiation.

Here, again, the radiance temperatures from $-60^{\circ} \mathrm{C}$ to $50^{\circ} \mathrm{C}$ are provided by an ammonia heat pipe blackbody with an emissivity of 0.9994 . For the calibration of thermal imagers a different heat pipe geometry with a larger aperture diameter of $75 \mathrm{~mm}$ was chosen. The radiance temperatures from $50{ }^{\circ} \mathrm{C}$ to $270{ }^{\circ} \mathrm{C}$ are provided by a water heat pipe blackbody with an emissivity of 0.9994 while the highest temperature range from $500{ }^{\circ} \mathrm{C}$ to $962^{\circ} \mathrm{C}$ is covered by a sodium heat pipe blackbody with an emissivity of 0.9996 . The temperature gap between the water and the sodium heat pipe blackbodies is covered by a large area plate radiator. The large area plate radiator has a temperature range from ambient temperature up to $600{ }^{\circ} \mathrm{C}$ with a radiating area of $300 \mathrm{~mm}$ by $300 \mathrm{~mm}$. An additional plate radiator with a circular radiating area with a diameter of $152 \mathrm{~mm}$ covers the temperature range from $-15^{\circ} \mathrm{C}$ to $120^{\circ} \mathrm{C}$. The achievable calibration uncertainties in the central area of the sensor arrays are identical with those for radiation thermometers, given that the 


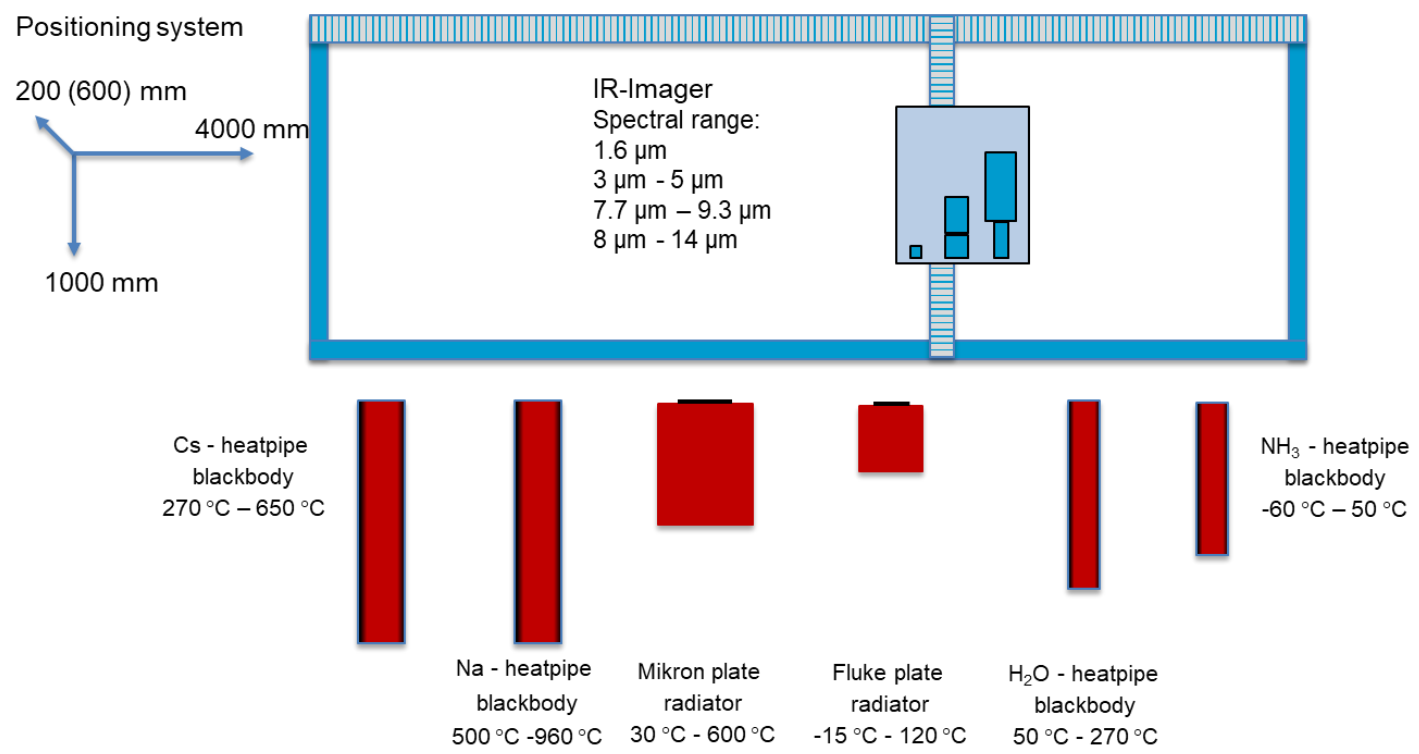

Figure 3 Schematic of setup of the calibration facility for thermal imagers.

radiation thermometer and the sensor array are sensing the same area of the radiator. When a thermal imager is calibrated, the device is placed in front of a heat pipe blackbody or plate radiator by means of a positioning system (see Figure 3 ). In the temperature range from $-60^{\circ} \mathrm{C}$ to $1000^{\circ} \mathrm{C}$ every desired radiation temperature can be set. For most thermal imagers the field of view is larger than the maximum aperture of the radiation source. In these cases, only the temperature reading of a certain part of the sensor array, e.g. the central area, is calibrated. A precise displacement of the imager relative to the radiator renders the possibility of the step by step calibration of the full detector area. In this case, stating the position and dimension of the calibrated sensor array becomes a crucial part of the calibration certificate.

a)

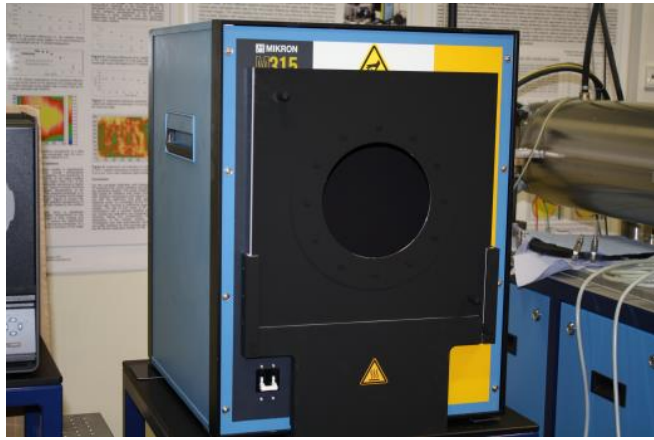

b)

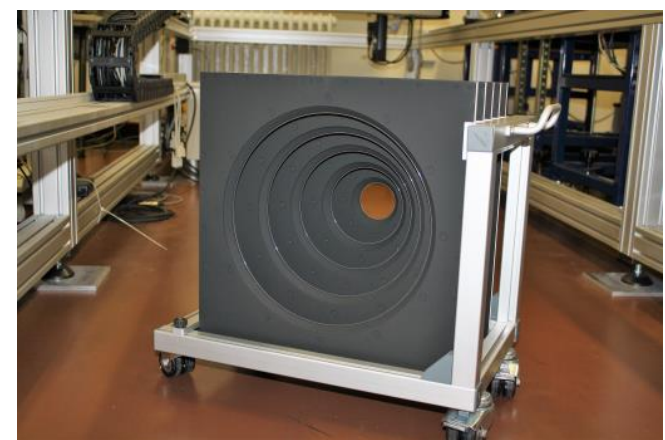
apertures for SSE measurements.

Furthermore, the plate radiators can be used to characterize the Size-of-Source Effect (SSE) of thermal imagers. At PTB, we have a set of exchangeable apertures that can be placed in front of the radiators to measure the SSE in the temperature range from $-15^{\circ} \mathrm{C}$ to $600^{\circ} \mathrm{C}$ (see Figure 4).

\subsection{Emissivity measurements}

At PTB two calibration facilities are operated to measure the emissivity in air and under vacuum. The Emissivity Measurement in Air Facility (EMAF) allows measurements in the temperature range from $25^{\circ} \mathrm{C}$ to $500{ }^{\circ} \mathrm{C}$ and in a wavelength range from $1.5 \mu \mathrm{m}$ to $50 \mu \mathrm{m}$ under angles of observation ranging from $0^{\circ}$ to $80^{\circ}$. The Reduced Background Calibration Facility (RBCF) [3] is used for radiation thermometry measurements under vacuum in the temperature range from $-170^{\circ} \mathrm{C}$ to $430{ }^{\circ} \mathrm{C}$ and emissivity measurements from $-40^{\circ} \mathrm{C}$ to $1000^{\circ} \mathrm{C}$. The RBCF (see Figure 5) is the ideal instrument for the calibration of remote sensing applications avoiding any atmospheric interferences [4]. At the RBCF the source chamber is connected to the detector chamber by means of a liquid nitrogen-cooled beamline. The radiation from different sources can be measured by radiation thermometers and a vacuum Fourier-transform infrared spectrometer. The RBCF employs two vacuum reference blackbodies, the Variable Low Temperature Blackbody (VLTBB) $\left(-173^{\circ} \mathrm{C}\right.$ to $\left.170{ }^{\circ} \mathrm{C}\right)$ and the Variable Medium Temperature Blackbody (VMTBB) $\left(80^{\circ} \mathrm{C}\right.$ to $\left.430^{\circ} \mathrm{C}\right)$. The temperature stability of the PRTs of the two blackbodies is typically better than $10 \mathrm{mK}$ over several hours and over the full temperature range. The emissivity 


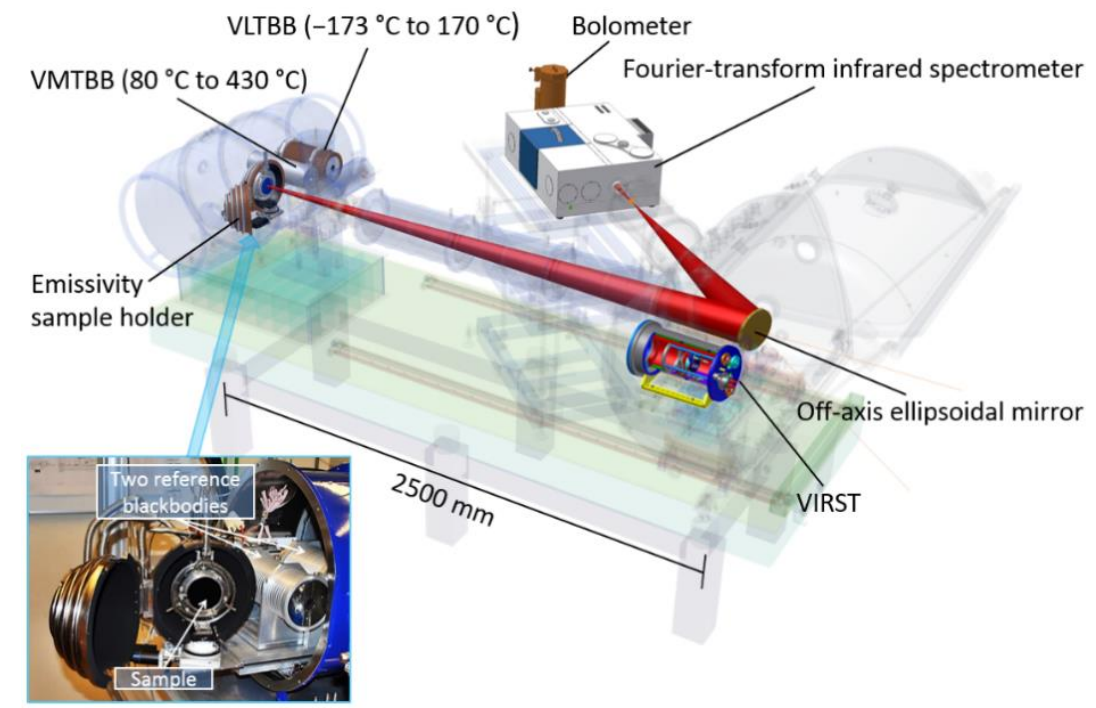

Figure 5 Transparent view of the reduced background calibration facility (RBCF) to illustrate the positions of the blackbodies VLTBB and VMTBB, the vacuum sample holder for emissivity measurements, the vacuum infrared standard radiation thermometer (VIRST) and the optical path of the radiation in the liquid nitrogen-cooled beamline.

of VLTBB is 0.9997 and the emissivity of VMTBB is 0.9996 . The consistency of the two blackbodies, within the combined standard uncertainty of $130 \mathrm{mK}$, has been validated in the extended temperature overlap region between $80^{\circ} \mathrm{C}$ and $170^{\circ} \mathrm{C}$. At the RBCF, the emissivity of high- $\varepsilon$ and of low- $\varepsilon$ samples (considering multiple reflections) can be measured for wavelengths from $1.4 \mu \mathrm{m}$ to $100 \mu \mathrm{m}$ and for observation angles from $0^{\circ}$ to $80^{\circ}$. From the spectrally and angularly resolved measurement of the sample emissivity the total and the total hemispherical emissivity can be, additionally, determined.

Due to the operation under vacuum conditions, the cooling of all critical components in the optical beam path with liquid nitrogen and the realization of a measurement scheme which cancels the remaining background an uncertainty level of 0.005 and better can be achieved. The spectral distribution of uncertainty has to be calculated for each individual measurement via a Monte-Carlo based method which is described in detail in [3].

Exemplarily a spectral emissivity measurement of $\mathrm{SiC}$ is shown to illustrate that the emissivity can be measured with a standard uncertainty $(k=1)$ of better than 0.005 . In Figure 6 the directional spectral emissivity of SiC observed at an angle of $10^{\circ}$ and at a temperature of $200^{\circ} \mathrm{C}$ is shown. The spectral distribution of the uncertainty is separately depicted as

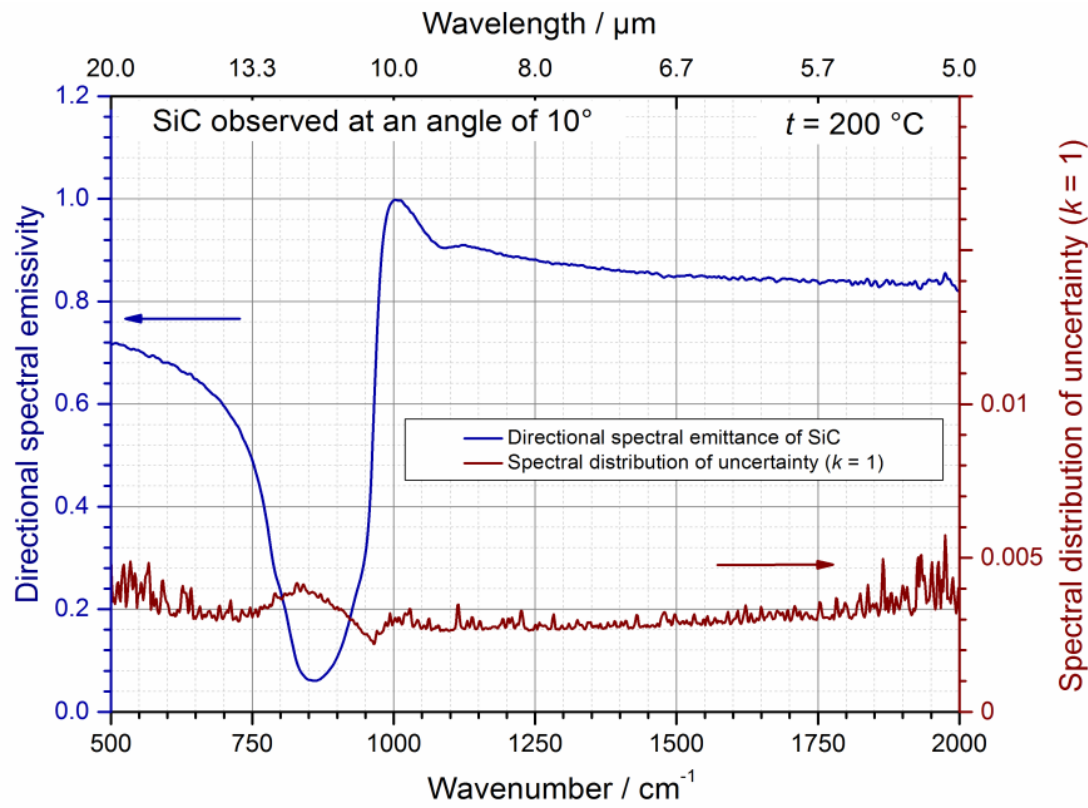

Figure 6 Directional spectral emissivity of SiC measured at a temperature of $200{ }^{\circ} \mathrm{C}$ and for an angle of observation of $10^{\circ}$ with respect to the surface normal. Additionally, the spectral distribution of the standard uncertainty is shown. The respective scale is on the right-hand ordinate axis. 
brown curve with the corresponding right-hand ordinate axis. The result confirms that even in the range from $11 \mu \mathrm{m}$ to $13 \mu \mathrm{m}$, where the emissivity of this sample and hence the signal is significantly reduced, the spectral distribution of uncertainty does not exceed the level of 0.005 .

Highly accurate measurements of the directional spectral emissivities of several widely used black coatings, which are often applied in different industrial and scientific applications, were recently performed at PTB and presented in detail in [3].

\section{Research and development}

Many applications in research areas such as remote sensing, earth observation or quantitative thermography require measurement tasks that are not covered by our routinely provided calibration and measurement service. To fulfil these demands there is the possibility to conduct joint research projects. Some examples of recent work are: support during the development and calibration of compact large area temperature radiators for the airborne limb sounder GLORIA [7] on HALO or the calibration of the onboard reference source of the MERTIS spectrometer on the BepiColombo mission to Mercury [8]. We also characterized samples and detectors equipped with vertical aligned carbon nanotube arrays (see for instance [9]) and calibrated the onboard calibration source for the German Spaceborn Imaging Spectrometer Mission EnMAP. These projects have very different needs and requirements regarding our instrumentation and, in addition, on the conditions in the labs such as different clean room classes, grounding requirements and the supply with clean gasses. Recently, we took a class 5 clean room into operation from which the RBCF is accessible ensuring that no unwanted contamination of the artefacts in our emissivity lab occurs.

\section{REFERENCES}

[1] Hollandt, J, Friedrich R, Gutschwager B, et al. High-accuracy radiation thermometry at the national metrology institute of Germany, the PTB., High temperatures, high pressures: $35 / 36$ (2004), $379-415$ http://dx.doi.org/10.1117/10.1068/htjr127.

[2] Gutschwager B, Taubert R D, and Hollandt J, Analysis of reference sources for the characterization and calibration of infrared cameras, International Journal of Thermophysics: 36 (2015), 2/3, 303 - 314, http://dx.doi.org/10.1007/s10765-014-1767-1

[3] Monte C, Gutschwager B, Morozova S P and Hollandt J,al. Radiation thermometry and emissivity measurements under vacuum at the PTB. International Journal of Thermophysics: 30 (2009), 1, 203 - 219 http:// dx.doi.org/10.1007/s10765-008-0442-9

[4] Monte C, Gutschwager B, Adibekyan A, Kehrt M, Ebersoldt A, Olschewski F and Hollandt J. Radiometric calibration of the in-flight blackbody calibration system of the GLORIA interferometer. Atmos. Meas. Tech. 2014, Vol. 7, pp. 13-27. https://doi.org/10.5194/amt-7-13-2014

[5] Monte $\mathrm{C}$ and Hollandt J. The determination of the uncertainties of spectral emissivity measurements in air at the PTB Metrologia, 2010, 47, S172-S181

[6] Adibekyan A, Kononogova E, Monte C and Hollandt J. High-Accuracy Emissivity Data on the Coatings Nextel 811-21, Herberts 1534, Aeroglaze Z306 and Acktar Fractal Black. Int J Thermophys (2017) 38 : 89. https://doi.org/10.1007/s10765-017-2212-z

[7] Olschewski F, Monte C, Hollandt J, et al. An in-flight blackbody calibration system for the GLORIA interferometer on board an air-borne research platformAtmos. Meas. Tech. Discuss., 6, 5529-5575, 2013, http://doi:10.5194/amtd-6-5529-2013

[8] Gutschwager B, Driescher H, Herrmann J, et al. Characterization of the $300 \mathrm{~K}$ and $700 \mathrm{~K}$ Calibration Sources for Space Application with the Bepicolombo Mission to Mercury Int J Thermophys (2011) 32:1429-1439 http://dx.doi.org//10.1007/s10765-011-0979-x

[9] Lehman J, Steiger A, Tomlin N, et al. Planar hyperblack absolute radiometer Optics Express: 24 (2016), 23. 